\title{
A methodological proposal to integrate the environmental impact assessment and the strategic environmental assessment in urban planning: the case of the Autonomous Community of Valencia
}

\author{
J. L. Miralles i Garcia \\ Department of Urban and Regional Planning, \\ Polytechnic University of Valencia, Spain
}

\begin{abstract}
The European Union (EU) promoted some important changes with the Directives to implement the Aarhus Convention and the Strategic Environmental Assessment. Spain developed the Directives with some Acts in 2006 and incorporated the sustainable development principle in land regulation, land planning, land activity, land transformation and land use with Acts in 2007.

However, in Spain, for environmental matters, the central laws regulate only a general framework and rules for central plans and programmes. The autonomous communities must approve any complementary laws with a detailed application, especially in urban planning matters. In this moment the Autonomous Community of Valencia (ACV) does not have any special regulation for strategic environmental assessment of urban planning, but, at the same time, the ACV publishes some acts for urban planning and approves guidelines concerning sustainability, citizens' quality of life and land planning. It is obliged to apply these guidelines to urban planning.

The new proceedings and documents that these new Laws require one to elaborate the Urban Plan are not foreseen in ACV legislation. All these matters generate a situation of juridical insecurity.

Anyway the Environmental Impact Assessment (EIA) and Strategic Environmental Assessment (SEA) have a special methodological relation. Paradoxically, urban plans in the ACV have been subject to EIA since 1999. There is therefore, a great experience on this matter with a type of environmental
\end{abstract}


impact evaluation that, in fact, is a kind of SEA. Nevertheless, a parallel process is taking place so as it concerns two completely different processes. That means that urban plans are subject to EIA and to SEA, but, in fact, there is a great confusion on the implementation of different instruments and proceedings with very similar objectives.

This paper analyzes the actual situation and proposes a methodological process for strategic environmental assessment in urban planning integrated with an environmental impact assessment.

Keywords: sustainable development, urban planning, natural resource management, environmental legislation and urban governance.

\section{Introduction}

In 2001 the European Commission approved the DIRECTIVE 2001/42/EC of de European Parliament and of the council of 27 June 2001 on the assessment of the effects of certain plans and programmes on the environment.

The Directive fixed the concept of "environmental assessment" as "the preparation of an environmental report, the carrying out of consultations, the taking into account of the environmental report and the results of the consultations in decision-making and the provision of information on the decision in accordance with Articles 4 to 9".

And article 3.5 established: "Member States shall determine whether plans or programmes referred to in paragraphs 3 and 4 are likely to have significant environmental effects either through case-by-case examination or by specifying types of plans and programmes or by combining both approaches. For this purpose Member States shall in all cases take into account relevant criteria set out in Annex II, in order to ensure that plans and programmes with likely significant effects on the environment are covered by this Directive".

So we have a general methodology of environmental assessment for any plan or programme undetermined or we can have a specify methodology for particularly plans or programmes.

Nevertheless, an important experience on environmental impact now exists for any types of plans. This is the case of urban planning. So in these cases it is necessary to adapt the general methodology in order to put into practice that experience.

Spain applied the European Directives that developed the Aarhus Convention in 2006, through the Act 9/2006 of April 28th for the Strategic Environmental Assessment (SEA) and the Act 27/2006 of July 18th for participation rights.

Anyway Spain ratified the European Landscape Convention of Florence in 2000 on November 26th 2007, published in an official publication (BOE) on February $5^{\text {th }} 2008$.

At the same time, the Valencian Autonomous Community published some acts for urban planning and urban management regulations: three laws and two regulations between 2004 and 2006 (see Miralles [1]) before the state's acts are published. One must remember that Spain has a hierarchy public administration for proposal legislation. Central administration has a competence for basic 
environmental legislation and the autonomous communities (17 altogether) have a competence for complementary environmental legislation and also an exclusivity legislation competence for urban and regional planning and management.

These laws incorporate an obligatory chapter of guidelines with normative and linking character to all town and country planning. These guidelines are part of the structural arrangement, having the denomination of Guidelines settled to define the strategy of urban evolution and occupation of the territory.

The guidelines are classified in three groups:

1. Guidelines concerning sustainability

1. Rational land use.

2. Efficient use of water resources, and protection of its quality.

3. Protection of natural media.

4. Conservation and valuation of cultural heritage.

5. Revitalization of rural heritage.

6. Prevention of natural or induced risks

7. Coastal arrangement.

2. Guidelines concerning citizens' quality of life.

1. Improvement of urban environments.

2. Public transport.

3. Public facilities.

4. Housing access.

3. Guidelines concerning land planning.

1. Fixing of substantive items for urban arrangement in Plan.

And finally, interesting regulations also exist about landscape for the European Landscape Convention (see Miralles [2]).

But, at this moment, the ACV does not have any regulation of SEA for complete state's laws in case of plans and programmes with regional regulation. This is the case of town and country planning. These plans are promoted by local or regional administration and are for final approval by regional administration.

The question (Ooi [3]) is to find an efficient and operative system for environmental assessment of town and country planning in order to get a sustainability development. It is necessary to find a proceeding system and an indicators system efficiently usable for decision-making.

\section{The experience of the Valencian Autonomous Community in the environmental impact of urban planning}

At the same time, the ACV legislated on environmental impact in 1989 and the act includes urban planning in a list of projects with environmental impact assessment. Really urban planning is not a project because it is a plan. But, in fact, urban planning has been subject to environmental impact assessment since 1989 (Act 2/1989, $3^{\text {rd }}$ March, of environmental impact (DOGV 8th March, 1989) and Decree 162/1990, 15th October, in order to develop regulation 2/1989 Act 
(DOGV 30th October, 1990)). And since 2005 a regulation has existed with a complete list of environmental values to check (Order 3rd January, 2005, about minimal contents of environmental impact assessment (DOCV 12th January, 2005). This order includes the case of urban planning). In fact, in this moment, urban planning must have a process of environmental impact assessment (in function of Valencian laws) and also a process of environmental strategic assessment (in function of states' laws).

So the Valencian regional civil service has a long experience in the environmental impact of urban planning.

The environmental impact assessment on urban planning in Valencia is in fact similar to strategic environmental process but there are differences and also some problems.

The principal difference is the procedure. Exactly the environmental impact assessment is on public exhibition with a complete version of plan where it is very complicated to change the decisions. So the population does not participate before the decisions are taken.

And there exists a serious problem; the final official environmental report is signed by the politician responsible. This responsible considers a technical assessment of civil servant but does not necessarily approve it. So an independent public institution to elaborate the final environmental report does not exist. Sometimes the final assessment depends on the politician responsible. And there has been a behavior in function to the interest of the moment but not in function to the interest for a long time (sustainability). This is a management problem.

\section{Specific environmental problem in spacial/land use planning}

There exist some different guides for general cases of strategic environmental assessment; for example the Scottish guide [3] or the OCDE guide [4]. There is also a guide for urban planning, such as an ENPLAN guide [5].

But the specific characteristics of spacial/land use planning produce special difficulty for a rigorous assessment of environmental problems.

The author would especially like to pay attention to three questions:

- Indefinable alternative. Where the administration promotes a spacial/land use plan, the proposals for the future urban and territorial model are in fact infinites. We can promote a plan for 10.000, 20.000, $50.000 \ldots$ future population with a big possibility for different combinations of infrastructures, public services and green zones localization. Rigorous comparative analyses between alternatives are not possible because an extraordinarily big number of possibilities exist.

- Ecological footprint externalization. All urban expansion (increase of population and/or economic activities) generates an increase of natural resources consumption and an increase of pollution emission (air, water, solid waste, ...). The natural resources and pollutions emissions are limited but generally with global limits, not local limits. The local 
population especially can use natural resources produced in other parts of the world (ecological footprint). In reality, the ecological footprint is an ecological larder. That is the surface of planet which produces the natural resources for consumption. We can consider this surface as a rural surface provision to guarantee the natural resources consumption of the society, especially city society. If we would like a sustainability society we need to guarantee the conservation of the ecological larder in order to produce the necessary natural resources for society. However, this is a global criterion. Generally, it is not possible to carry out this criterion at a local level.

- Irreversibility of construction process. All transformation of rural land on urban land is practically irreversible. So the transformation of ecological larder surface on the urban surface or artificial surface mean its irreversible destruction; non correction impact. Where we have a decision of urban land use and finally on producing the transformation rural surface to urban surface, to change the situation it is almost always impossible. In particular, the process of urban sprawl in Europe produces an important irreversible situation of rural areas transformation.

Fisher [7] describes the general situation of SEA in spacial/land use planning in the 25 member states of the EU. A lot of member states have initiatives to implement the SEA in spacial/land use planning but often do not have rigor and the degradation of environmental values in the European territory continue. This is the case in Spain and the Valencian Community.

\section{Criterion for new system of strategic environmental assessment for spacial/land use planning}

In urban planning we have two basic situations:

- New urban development

- Actuation in the city what exists or urban land

In the case of new urban development, the transformation of rural land to urban land is always an irreversible process. And all process of rural land transformation to urban land means an increase of natural resources consumption and an increase of pollution emissions. So the question is: Where is land transformation acceptable? The response for this question is the Territorial Aptitude Method for Sustainable Urban Development (TEAMSUD) [7, 8].

The territorial aptitude is the synthesis between capacity and vulnerability for certain use, in each homogeneous zone of a territory. So, each homogeneous zone in a territory can show three basic levels of capacity (without limits, with surpassed limits and with no surpassed limits) and three basic levels of vulnerability (assumable impact, correctable or critical). The combinations between these present different possible situations concerning the sustainability of transformation process. 
The method by a GIS system enables us to identify the surface of natural resources and surface with any risk and so identify the better zones for new urban development and the sustainability situation in each case.

This is a good method for alternative analysis because it enables us to identify the zones acceptable for a sustainable urban development (without significant destruction of natural resources and without serious risk).

Besides the new urban activities and the urban activities in a previous city must be conditioned to the objective of the diminution of natural resources consumption and pollution emissions.

Of course, the plan must carry out the strategic plans or programmes of European or State administration and must incorporate the environmental criterion of any different offices of administration.

\section{Hierarchy environmental assessment}

Generally in the different regional country of Spain, the spatial and land use planning are organized in a hierarchy system. The municipal urban plan has a basic finality of the structural planning for all territory of municipality objective (working scale of about 1:10000). This municipal urban plan will be development in detail (working scale of about 1:2000) with another zonal urban plan (urban plan for developing a new urban area, urban plan for renovation city zone, urban plan for specifically objective as any infrastructure, green zones, ...). And finally the zonal urban plan will be integrated executed by zones, actuation or execution units, in order to realize public works of urbanization.

So the main environmental objectives in structural plan are:

- To identify the natural resources to conserve for a long time.

- Risk prevention.

- To confirm general availability of urban services (water, sewage treatment, electric energy, transports, ...)

- To confirm general availability of public services or land use prevention for new requirements (education, sanitation, sports, ...)

- Land use prevention for green zones.

- To conserve heritage.

And the main environmental objectives in zonal development plan are:

- To confirm particular availability of urban services and their connection with the net of general infrastructures.

- Land provision for public services, public spaces and green zones.

- Determine environmental criterion for later application in building and public works.

The process of urbanization finishes when one builds the planned public works. They are defined in the urbanization project. In figure 1 we can see a diagram of general process. The structural and zonal urban plan has a strategic environmental assessment (SEA) and the urbanization project has its environmental impact assessment (EIA). This diagram carries out the art 4.3 of Directive 2001/42/CE. 


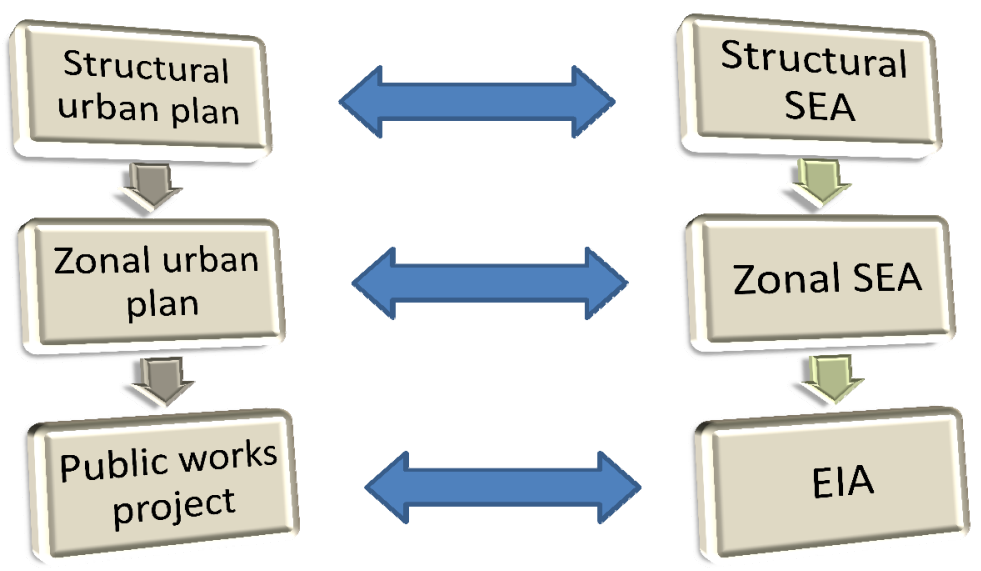

Figure 1: Diagram process of urbanization with plans and projects and their environmental assessment.

\section{Methodological process for SEA of urban plan}

Now we pay attention to the structural urban plan. In figure 2 one can see a proposal for strategic environmental assessment associate a process for elaborating a strategic urban plan. The strategic urban plan has as objective to define the structural elements of spatial planning for town and country.

Generally, in Spain, the urban municipal plan is the principal instrument for urban planning and it determines structural planning for all the territory of municipality. Habitually, this type of plan also has a detail urban planning for a city area (urban area what exist). And generally the process of urban planning is a public initiative of local administration.

In figure 2 one can see in the left column, the phases and in the right column, the documents produced.

After starting the process we have a period to elaborate a draft plan. This is a simplified version of the plan because it is a working document for decisionmaking and so can change the territorial model proposed.

This first draft plan includes only one proposal or alternative. Is a proposal territorial and urban model for the future as a whole of the environmental analysis and the political objective of responsible local administration.

This proposal is a document for consultation with another authority and public in the public participation process.

It is recommended elaborating a Public Participation Plan in the starting moments of process for planning all activities in order to process public consultation.

In the first phase the environmental analysis includes: 
- Territorial Analysis of Aptitude (TEAMSUD) in order to identify the natural resources to conserve for a long time and to identify zones for risk prevention.

- Public evaluation of landscape unit to consider the results on landscape planning (territorial and urban).

- General public evaluation of urban problems to raise in the urban planning process.

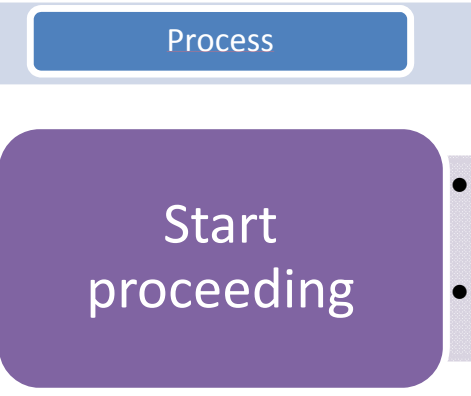

- Draft simplified version of structural plan

- First environmental report

\section{Consultations} and Decisionmaking

- Final simplified version of structural plan

- Second environmental report

\section{Final Consultation}

- Final version structural plan

Figure 2: Diagram of methodological process for SEA of strategic urban plan. 
For example, in ACV the environmental questions for analysis (environmental inventory) in spatial planning are:

- Generally all environmental values affected by plan as fauna, flora, vegetation, geology, soil, water, air and landscape.

- Actual uses.

- Rural road traditionally used for farming.

- Environmental risks: flood risk, pollution risk of aquifer, fire forest, erosion, seismic risk, geological risk.

- Environmental units.

- $\quad$ Forest zones affected by fire.

- Environmental degraded zones.

- Zones of interest for nature conservation.

- Actually population, water consumption, sewage produced and urban solid wastes produced.

- Cultural, archaeological and ethnologic heritage.

Also in ACV it is obliged to realize a Landscape Study. This study includes the delimitation of landscape units for public evaluation and a Public Participation Plan associated to the urban plan. Moreover, other Valencian laws oblige us to realize other studies (acoustic study, sustainable mobility study, ...) and any criterion of sustainability (compact model of town, ...)

Obviously, the environmental report always must be carried out with the contents in Annex I of the Directive.

With the environmental analysis it is possible to propose a territorial and urban model for the future compatible with environmental values. This proposal is the draft plan for a consultation (phase II).

After this phase of consultation with the authority and public (art 6 of Directive) on modifying the first proposal to incorporate the results of consultation to another authority and the results of consultation to the public if possible. Although we have only one alternative, it is always possible to compare with zero alternative (not promote the plan). This is the process of decisionmaking for strategic proposal.

So we generate a second simplified version of a structural plan with a second version of environmental report (with results for approval. A double approbation is necessary: the approbation of municipality and the approbation of a superior administration level in order to check the correct legal contents and correct legal proceedings.

When this second version is approved can start the nest phase: complete documentation for urban plan (detail map, urban normative, complete analysis, detail definition of management system, ...).

When the complete version of the plan is finished, we must proceed to another phase of consultation to inform of the final result and to make the last changes possible.

The process finishes with the double approbation of the final urban plan. 


\section{Conclusion}

The Directive 2001/42/EC of the European Parliament and of the Council of $27^{\text {th }}$ June 2001 on the assessment of the effects of certain plans and programmes on the environment establishes a general system for strategic environmental assessment of plans and programmes. But in the case of spatial and land use planning, a specific contents and proceeding for consultation is necessary. This situation is envisaged in the same Directive. Also each Member State of the EU can regulate specific proceedings for consultation. The experience in Spain and in the Valencian Autonomous Community provides us to generate an approach for a general methodology in SEA for urban planning.

\section{References}

[1] Miralles i Garcia, J.L. The introduction of the sustainability in the procedures regulated for urban planning: the case of the last act on urbanism, territory and landscape in the Valencian Community (Spain). Sustainable Development and Planning III. A. Kungolas, C.A. Brebbia \& E. Beriatos (Eds), WIT Press, Southampton, pp 505-513, 2007.

[2] Miralles i Garcia, J.L. Landscape management Case Study: the situation in the Autonomous Community of Valencia (Spain). Proceedings $1^{\text {st }}$ WSEAS International Conference on LANSCAPE ARCHITECTURE. New aspects of Landscape Architecture. T. Panagopoulos \& J.B. Burley (Eds), WSEAS Press, Algarve (Portugal), pp 17-22, 2008.

[3] Ooi, G.L. Sustainability and Cities. Concept and Assessment. Institute of Policy Studies and World Scientific, Singapore, pp 1-26, 2005.

[4] A Practical Guide to Strategic Environmental Assessment Directive; Scottish Executive, Welsh Assembly Government, Department of the Environment, Northern Ireland, Office of the Deputy Prime Minister: London. ODPM Publications: West Yorkshire, 2005. www.odpm.gov.uk.

[5] Applying Strategic Environmental Assessment. Good Practice Guidance for Development Co-operation. Organisation for Economic Co-operation and Development (OCDE). OCDE Publications: Paris, 2006. On line: www.sourceoecd.org/development/9264026576

[6] ENPLAN www.interreg-enplan.org

[7] Fischer, T.B. 2006. SEA in spatial/land use planning in the 25 member states - a July 2006 update, UVP report 20 (3): 127-131.

[8] Miralles i Garcia, J.L. An operative proposal for the implementation of the concept of sustainability in Urban Development. Conservation and Urban Sustainable Development: A Theoretical Framework. Editora Universitaria Universidade Federale de Pernambuco, Recife, pp 195-206, 1999.

[9] Miralles i Garcia, J.L. \& Altur Grau, V. Applied methodology in GIS support for the definition of territorial ability to Sustainable Development. Proceeding International Conference Environmental Challenges in an Expanding Urban World and the Role of Emerging Information Technologies. CNIG - National Centre for Geographical Information, Lisbon, pp 179-188, 1997. 